\section{Opinions in Plasmonics}

\author{
Chris D. Geddes ${ }^{1}$
}

Published online: 16 January 2020

(C) Springer Science+Business Media, LLC, part of Springer Nature 2020

Dear Plasmonics Community,

I would like to start this brief editorial by wishing everybody and their families a very happy New Year for 2020 and a healthy and prosperous new decade.

While Plasmonics is a relatively young scientific discipline over the last 25 years or so, we have seen significant growth in its utility and applications. One can certainly hope that our community is awarded a Noble Prize or two in years to come for the tremendous gains that have been made in the Plasmonics field.

During discussions with journal editors, colleagues, and friends at conferences, it is clear that our rapidly growing community has many opinions and important discussions, not only on worthy candidates for Noble Prizes and emerging scientific disciplines but also on publishing and scientific policies, best academic practices, employment, ethics, entrepreneurialism, and a whole host of other topics. Subsequently, to capture these valuable opinions and discussions related to Plasmonics, I am introducing a new article class into the Plasmonics Journal, namely "Opinions."

"Opinions" in Plasmonics articles will be reviewed by the editors and the editorial board. Initially they will be invited, but the journal also welcomes random solicitations. Authors are encouraged to discuss their topic and content with the editor-in-chief (Professor Chris D.
Geddes, Geddes@umbc.edu) before submitting. Additional information can be found below:

- There is no length restriction of articles.

- The content can be focused on Plasmonic techniques and emerging disciplines, but self-serving articles are discouraged.

- The content can include scientific and publishing policy.

- The content can include discussions on education, training, ethics, employment, and entrepreneurialism.

- The articles are not intended to replace other peer reviewed article types.

- Figures are welcome

I hope you all find these new articles informative and as always, please e-mail me with any questions.

Best,

Dr. Chris D. Geddes

Professor

University of Maryland Baltimore County, UMBC

January 3, 2020

geddes@umbc.edu
Chris D. Geddes

geddes@umbc.edu

1 The Institute of Fluorescence and the Department of Chemistry and BioChemistry, The Columbus Center, 701 East Pratt St,

Baltimore 21202, USA 